OPEN ACCESS

Edited by: Shwetal Mehta,

Barrow Neurological Institute,

United States

Reviewed by:

Monica Venere,

The Ohio State University

Columbus, United States

Bozena Kaminska

Nencki Institute of Experimental

Biology, Poland

*Correspondence: Rainer Glass

rainer.glass@med.uni-muenchen.de;

Krishna P. L. Bhat

kbhat@mdanderson.org

tThese authors have contributed equally to this work.

Specialty section: This article was submitted to Neuro-Oncology and Neurosurgical Oncology, a section of the journal Frontiers in Oncology

Received: 27 March 2017 Accepted: 20 June 2017 Published: 10 July 2017

Citation:

Audia A, Conroy S, Glass R and Bhat KPL (2017) The Impact of the

Tumor Microenvironment on the Properties of Glioma Stem-Like Cells.

Front. Oncol. 7:143. doi: 10.3389/fonc.2017.00143

\section{The Impact of the Tumor Microenvironment on the Properties of Glioma Stem-Like Cells}

\author{
Alessandra Audia ${ }^{1 \dagger}$, Siobhan Conroy ${ }^{1,2 \dagger}$, Rainer Glass ${ }^{3,4 *}$ and Krishna P. L. Bhat ${ }^{1,5 *}$ \\ ${ }^{1}$ Department of Translational Molecular Pathology, University of Texas, M.D. Anderson Cancer Center, Houston, TX, United \\ States, ${ }^{2}$ Department of Pathology and Medical Biology, University Medical Center, Groningen, Netherlands, ${ }^{3}$ Neurosurgical \\ Research, Department of Neurosurgery, University Hospital, LMU Munich, Munich, Germany, ${ }^{4}$ German Cancer Consortium \\ (DKTK) partner site Munich and German Cancer Research Center (DKFZ), Heidelberg, Germany, ${ }^{5}$ Department of \\ Neurosurgery, University of Texas, M.D. Anderson Cancer Center, Houston, TX, United States
}

Glioblastoma is the most common and highly malignant primary brain tumor, and patients affected with this disease exhibit a uniformly dismal prognosis. Glioma stemlike cells (GSCs) are a subset of cells within the bulk tumor that possess self-renewal and multi-lineage differentiation properties similar to somatic stem cells. These cells also are at the apex of the cellular hierarchy and cause tumor initiation and expansion after chemo-radiation. These traits make them an attractive target for therapeutic development. Because GSCs are dependent on the brain microenvironment for their growth, and because non-tumorigenic cell types in the microenvironment can influence GSC phenotypes and treatment response, a better understanding of these cell types is needed. In this review, we provide a focused overview of the contributions from the microenvironment to GSC homing, maintenance, phenotypic plasticity, and tumor initiation. The interaction of GSCs with the vascular compartment, mesenchymal stem cells, immune system, and normal brain cell types are discussed. Studies that provide mechanistic insight into each of these GSC-microenvironment interactions are warranted in the future.

\section{Keywords: glioma stem-like cells, glioblastoma, microenvironment, transdifferentiation, therapy resistance}

\section{INTRODUCTION}

Our view of cancer has changed ever since the discovery of cancer stem cells (CSCs) (1). CSCs are a proportion of cells within the bulk tumor and are similar to normal stem cells in their ability to self-renew and differentiate into downstream lineages. These cells exhibit tumor-initiating potential compare to the non-CSCs counterpart or differentiated progeny (2). CSCs have revolutionized our understanding of tumor biology and have had a strong impact on strategies for tumor treatment. However, the criteria to clearly define CSCs are well established in some tumors (for, e.g., leukemias), but are less clear for primary brain tumors such as glioblastomas (GBMs) (3-5). Glioma stem-like cells (GSCs) in GBM were first described about decade and a half ago (6-8). Since then, many studies have not only confirmed their existence but also identified additional attributes to these cell types including contribution to therapy resistance $(9,10)$. Numerous alternative terminologies have been used for GSCs including glioma-initiating cells, glioma stem cells, and glioma tumor propagating cells. The inherent difficulties to up-front identify stem-like cells in GBM has stirred a long (and ongoing) debate about the nature, pathological impact, and therapeutic value of GSCs $(11,12)$. Furthermore, the population dynamics of these cells with cell fate conversion and retention of stem-like properties perhaps by de-differentiation further complicates matters. In order 
to treat this highly malignant disease, a better understanding of these cells is necessary. Furthermore, due to the therapeutic resistance of GSCs, understanding not only the inherent resistance mechanisms but also the contribution of the surrounding microenvironment could be considered as an interesting alternate approach. Interactions of GSCs with the microenvironment not only contributes to maintenance of the stem-like state of the cells that eventually leads to clonal expansion but also acquires aggressive traits including migration, invasion, and therapy resistance. In this review, we will discuss the cell types present in the tumor microenvironment and the type of interactions with the microenvironment that influence expansion of GSCs. We will focus primarily on studies that have examined GSCs in the context of the microenvironment, but studies that by definition have not examined the stem cell component in tumor cells have also been included in some cases where there is insufficient literature on GSC interaction with a specific cell type.

\section{CSCs IN GBM}

For a better understanding of the microenvironment, it is imperative to first briefly comprehend the history and the controversies underlying the fundamental definition of CSCs in GBM. Several detailed reviews exclusively focused on GSCs have already been published $(11,13)$. Here, we present a general opinion on the current state of the GSCs. A robust definition for a GSC may follow established biological criteria that are generally applied to all stem cells (including non-tumorigenic stem cells), which is, the ability to clonally expand and to give rise to more differentiated progeny (14). For GBMs, these criteria were first applied by Peter Dirks (15), thus identifying GSCs, which were also endowed with tumor-initiating capacity. This seminal study identified a marker (prominin, CD133) to purify GSCs and to test stemness properties. Using the tumor-initiating capacity as a benchmark for CSC has been tricky since this feature is assayed by tumor implantation experiments using decreasing numbers of GSCs to monitor tumor take in cells positive or negative for cell surface markers (15). However, not all studies strictly adhere to these benchmarks. Ever since this first publication, the field of GSCs has exploded with its share of great advances and controversies. First, using CD133 as a standalone marker has not been a successful and reproducible strategy. This, in part, could be attributed to the rapid alteration of stem cell $\left(\mathrm{CD} 133^{+}\right)$populations in extended in vitro cultures. However, CD133 negative populations from freshly dissociated tumors have been also shown to form tumors at similar rates as $\mathrm{CD} 133^{+}$cells and additional markers for defining GSCs have been proposed (11). Also, it is noteworthy that CD133 undergoes $\mathrm{N}$-glycosylation upon cellular differentiation, whereas and many studies have been examining changes in mRNA expression which bears no relevance to stemness (16). More importantly, GSCs from a single GBM can express multiple markers and tumor-initiating potential of each of these populations can vary (17). Second, the proportion of GSCs in a GBM may vary substantially between GBM of different individuals (18) prohibiting a generalized method to quantify, compare, and thereby standardize the aggressiveness of GSCs from different donors in xenograft transplantation assays. Diversity in GSC subtypes is likely associated with the established intratumoral heterogeneity of GBM (19), which is propelled by clonal evolution generating different tumor areas (within the same tumor) that are predominated by progeny from different tumor cell clones $(20,21)$. The coexistence of evolutionary evolved and genetically distinct tumor subfields in one GBM is a relatively recent observation and was previously not routinely taken into account in studies using GSCs. Third, the interest in research in GSC biology is high, since, apart from a potential role in tumor initiation and relapse (22), GSCs have been attributed with other clinical problems such as resistance to radiation $(9,10)$ or chemotherapy $(23,24)$. These are all important points adding to the pathological potential of GSCs and can support the notion that GSCs are a major cell entity that forms recurrent tumors after multi-modal treatment. However, therapeutic resistance cannot serve as a defining criterion of GSC as there is ample heterogeneity also in therapy response of GSCs $(10,25)$ and high therapeutic resistance can as well be detected in more differentiated GBM cells [non-GSCs (26)]. Despite these controversies and differences, GSCs are central in our understanding of GBM biology.

\section{THE EFFECT OF THE VASCULATURE ON GSC PROPERTIES}

\section{Endothelial Cells}

The major neural stem cell pools in the adult mammalian brain are confined to the subventricular and subgranular zones, each with a defined set of surrounding cells that protect their stemlike state (27). The brain tumor stem-like cells were first reported to preferentially reside in the perivascular niche (28). Increased numbers of endothelial cells expanded the fraction of stem-like cells, and conversely in vivo blood vessel depletion through anti-angiogenic agents considerably slowed tumor growth and decreased the count of self-renewing and multipotent cells (28). The site where stem-like cells generally reside is considered relatively hypoxic, an environmental cue that is transcriptionally converted by cells into stabilization of hypoxia-inducible factor (HIF- $1 \alpha)$. In glioma cells, both HIF- $1 \alpha$ and HIF- $2 \alpha$ enhance glioma sphere formation and cell proliferation, induce stemness, and increase tumor initiation ability $(29,30)$. Besides affecting the GSCs themselves, the stabilization of HIF-1 $\alpha$ profoundly affects the vascular compartment through the induced secretion of VEGFA (9), which creates a gradient for the developed vessels, coordinating tip cell selection and stalk elongation in endothelial cells, and promoting endothelial sprouting or angiogenesis (31).

In addition to VEGFA, other angiogenic signaling molecules such as endothelial cell-bound ligands DLL4 and Jagged-1 can bind the Notch receptors expressed on GSCs. Blockade of Notch signaling in xenograft GBMs through $\gamma$-secretase inhibitors inhibits tumor growth establishing a role for Notch signaling for GSC maintenance and tumor growth $(32,33)$. Adjacent localization of $\mathrm{Nestin}^{+}$and Notch ${ }^{+}$tumor cells and Notch ligand expressing endothelial cells was observed in primary GBMs (34). Co-culturing of endothelial cells with GBM neurospheres enhanced cell growth, which could be inhibited through knockdown of these endothelial ligands. Nitric oxide (NO) is another signaling molecule that is produced by endothelial cells. 
$\mathrm{NO}$ is produced from the substrate $\mathrm{L}$-arginine through a family of NO synthases, of which the endothelial isoform is denominated eNOS. In GBMs, eNOS expression is elevated and correlated with increased tumor growth $(35,36)$. PDGF-driven eNOS $^{-/}$glioma bearing mice prolonged survival in vivo and decreased Notch signaling, hence establishing the GSC beneficial effects of Notch signaling described above through another route. Conservation of this pathway in PDGFR-amplified human glioma specimens was also shown.

In addition to the bi-directional interaction between GSCs and endothelial cells, GSCs directly impact vasculature through transdifferentiation mechanisms. GSCs have been shown to generate functional vasculature, acquire endothelial-like properties both in vitro and in vivo, and ablation of the transdifferentiation process slowed tumor growth $(37,38)$. The acquisition of the CD105 endothelial marker expression was shown to be controlled by Notch signaling and endothelial cells were shown to harbor genomic aberrations similar to those observed in the tumor cells. A recent study showed glioma cells transdifferentiating into endothelial cells in a p53-inactivated/AKT-driven glioma model under epigenetic control of the WNT signaling pathway (39). This study reported that the endothelial transdifferentiation was specifically observed at the invasive site of the tumor in contrast to earlier studies that showed the presence of endothelial cells from human origin in the core of the tumors. However, follow-up clinical studies could not confirm the widespread EGFR amplified CD34 ${ }^{+}$ endothelial cells in gliomas (40), and hence transdifferentiation, while important, may be a rare event in the evolution of gliomas.

\section{Pericytes}

Pericytes are vascular smooth muscle cells that provide support, maintain vascular integrity, stabilize the vessels, and prevent vascular leakiness (41). While the exact contribution of pericytes to GSC self-renewal and tumor initiation is still unknown, GSCs were recently shown to transdifferentiate into pericytes (42). Using lineage specific reporters, it was demonstrated that pericytes were GSC derived. GSCs were recruited by SDF-1 signals from endothelial cells and were subsequently transdifferentiated into pericytes on-site under the influence of TGF- $\beta$. The contribution of GSCs to the pericyte pool was estimated to be substantial, with an average of $78 \%$ of pericytes carrying the tumor marker. Once again, this notion has been challenged in other pericyte reporter mouse strains that were used as glioma models. In one study, researchers used transgenic animals expressing GFP under control of the pericyte-associated signaling molecule $G$ protein signaling 5 (RGS5-GFP) (43) and did not detect any contribution of syngeneic glioma cells (GL261 cells) to perivascular structures. Likewise, when implanting a mouse glioma cell line into a dual fluorescence pericyte reporter animal model (44), the pericytes appeared to be derived from the host tissue. The mouse glioma cell lines/models used in these two studies may not truly represent GSCs, which can explain why there is no strong transdifferentiation of tumor cells into pericytes. However, these reports suggest that transdifferentiation of GSCs is at least no prerequisite for the formation of new pericytes in GBM. Further studies using models that mimic the actual physiological tumor more closely are warranted in the case of transdifferentiation studies.

\section{Normal Brain-GSC Interactions}

The adult brain is mainly composed of astrocytes, neurons, and oligodendrocytes. The role of these cells in tumor initiation and maintenance are relatively understudied, but the few studies that are available indicate that they do have an important role in GBM biology $(45,46)$. Around $50 \%$ of the brain cells are astrocytes, which serve a multitude of functions in homeostatic maintenance (47). In response to injury or surgery, astrocytes can become activated and are often termed reactive astrocytes (48). GSCs were able to decrease $\mathrm{p} 53$ expression in the surrounding reactive astrocytes, thereby making them acquire a tumor-permissive or even promoting phenotype (49). Astrocytes surrounding a xenograft express higher levels of Connexin 43 that facilitates glioma invasion (50). Astrocyte injury also caused transcriptome and secretome alterations in vitro, and enhanced GBM cell proliferation and invasion (51). The role of neurons and oligodendrocytes on GSC biology are less known, but a recent report showed that neuronal activity-induced secretion of neuroligin-3 promotes gliomagenesis (52). Although these effects were not studied using GSCs, further studies are required to confirm and elaborate on the findings of the few available reports that indicate that normal brain cell types play an important role in GSC functions.

\section{The Immune Microenvironment Surrounding GSCs}

With the advent of immunotherapy, the past few years has seen an explosion of studies describing the immune system and its critical role in cancer pathogenesis $(53,54)$. However, the immune regulation of brain tumors, in the context of GSCs, is not fully established. It should be noted that one major caveat in studies involving GSCs is that tumor initiation and evolution is studied in xenograft bearing mice that have greatly reduced number of $\mathrm{T}$ cells, and therefore, studies involving GSCs and the immune system can never be physiologically complete.

Although for decades the brain has been considered as immune privileged, owing to an intact blood-brain barrier and the "absence" of lymphatic drainage system, recent discoveries prove the existence of a direct communication between the CNS and the immune system. A variety of immune cell types including microglia and macrophages, $\mathrm{T}$ lymphocytes, and dendritic cells (DCs) are found in the brain and play a role in immune surveillance (55). The activation of the immune system or its suppression in the GBM microenvironment depends on cell type/ function and on the presence/absence of immune signals in the local environment.

\section{T Lymphocytes}

Some earlier studies describing the role of immune cells in GSCs have been generally shown to silence the immune response, escape immune surveillance, for instance, with an ineffective tumor antigen presentation, or release and recruitment of on-site immune suppressive factors (such as TGF- $\beta$ ) and immune suppressive cells (such as immunosuppressive B-cells and myeloid cells) (55). Studies have shown that GSCs can mimic antigen-presenting cells in their expression of major histocompatibility complex I (MHCI). GSCs can either regulate the level of expression of the MHC I 
complex (56) or express the inhibitory co-stimulating molecule B7 homolog 1 (also known as programmed death ligand 1) and lack the expression of the activating co-stimulating molecules CD40, CD80, and CD86. Without MHC I expression or costimulating factors, cancer cells fail as antigen presenting cells or induce T cells to anergy following antigen presentation, rendering them incapable of being activated. PD-L1 has been shown being upregulated in the GBM microenvironment and it seems to be more associated with the mesenchymal subtype $(57,58)$.

In addition to expression of co-inhibitory molecules, alternative mechanisms of $\mathrm{T}$ cell inhibition exist. Regulatory $\mathrm{T}$ cells (Tregs) are a form of $\mathrm{T}$ cells that are immunosuppressive and generally inhibit the expansion of effector T cells. This is attributed to constitutive activation of cytotoxic T-lymphocyte-associated protein 4 (CTLA-4), which contributes to their ability to suppress the immune system (59). The ligand CD95 (Fas/apoptosis antigen 1 ) is expressed on GSCs and induce apoptosis of Tregs and reduce the number of infiltrating $\mathrm{T}$ cells in the tumor microenvironment $(60,61)$. Similarly, CTLA-4 present on activated Tregs can bind CD28 and induce T cell anergy (62). An interesting crosstalk mechanism between GSCs and T cells is the secretion of galectin-3 triggered apoptosis in both naïve and activated $\mathrm{T}$ cells promoting the expansion of the CSCs and therefore their immune suppressive role $(63,64)$. Alternatively, GSCs cause immunosuppression in the glioma microenvironment by activating the STAT3 pathway and by increasing the number of Tregs (65). On these lines, it has been shown that GSCs secrete more TGF- $\beta$ than their differentiated counterparts (66). TGF- $\beta$ is involved in the down-modulation of MHC II expression and subsequent antigen processing and in the expansion of immune suppressive Treg cell population and perhaps is one additional mechanism by which GSCs modulates Tregs (67). Once again, it is noteworthy that owing to the heterogeneity, not all GBMs show a significant infiltration of Tregs in the microenvironment, suggesting heterogeneity also in the immune suppressive mechanisms. This emphasizes the necessity to study GSC interaction with T cells at the single cell level as well as distinguishing them according to their subtype and mutation profiles. In order to do so, novel mouse models are required that could better represent the heterogeneity of this tumor in vivo.

\section{Microglia and Macrophages}

In addition to secreting immune suppressive cytokines, GSCs are capable of recruiting or modulating immune cells with tumor supportive phenotype. GBMs are characterized by a very high infiltration of macrophages, phagocytic cells that engulf cellular debris and foreign substances. Microglia, are resident macrophages that present the first line of defense in the CNS. Both microglia and infiltrating macrophages (myeloid cells) can represent between 13 and $43 \%$ of the tumor mass in different animal models for GBM (68) and in freshly isolated GBM biopsies a myeloid cell content of approximately 8\% (69) was detected in FACS analyses, while in immunohistochemical studies, often a myeloid cell content ranging from 20 to $50 \%$ of the total cell mass is reported (70), which we (according to our experience) consider as representative.

In classical immunological experiments, investigating, e.g., the response of myeloid cells to toll-like receptor agonist (like lipopolysaccharides) or to chronic inflammatory stimuli, myeloid cells are often grouped into two different immune phenotypes named M2 (which is representative for the chronic inflammatory state) and M1 (which includes all classical pattern of inflammation) (71). In many different peripheral cancers, the attribute of an M2-shifted immune response of tumor-associated macrophages (TAMs) indicates a more tumor-supportive function that is associated with a myeloid cell signaling pattern that is highly reminiscent of the chronically activated state myeloid cells (71). The phagocytic role of TAMs (or glioma-associated macrophages/ microglia) has been controversial. While one study showed a lack of phagocytic activity of these cell types (72), and their secreted cytokines, such us IL-6 and IL-10, can promote cancer cell proliferation (73), other studies have shown that factors secreted by glioma cells can promote phagocytosis, and proliferation of microglial cells (74). Unlike their more differentiated progeny, GSCs show an increased capacity of active chemo-attraction and recruitment of macrophages in vitro through the secretion of cytokines. These include colony-stimulating factor-1 (CSF-1), C-C motif ligand-2 (CCL-2), and macrophage inhibitory cytokine 1 , factors enriched in GSC-conditioned media. Moreover, the secretion of CSF-1 and CCL- 2 by the GSCs resulted in a polarization of the macrophages toward the M2 immune suppressive phenotype. Other CSC-secreted factors include IL-10 and TGF- $\beta$, which also suppress tumor-associated microglia/macrophage function and generate a more immunosuppressive (M2) phenotype (75). TAMs in GBM have been shown to be recruited by periostin, a protein preferentially expressed by GSCs (76). Periostin functions as a potent chemo-attractant of monocyte-derived macrophages from the blood to the tumor microenvironment and maintain the M2 immune suppressive phenotype to promote tumor growth. In fact, the disruption of periostin in vivo shows a reduction in the recruitment of tumor-supportive TAMs (M2 subtype), inhibition of tumor growth, apoptosis of GSCs, and increase of survival in a xenograft mouse model. Another molecule with crucial role in this transition is SPP1 (osteopontin). SPP1 is a secreted protein that shares similarities in features and mechanism of action with Periostin and contributes to the maintenance of an immune suppressive environment. It has been shown, in fact, to be highly expressed in M2 polarized macrophages and GBM-infiltrating $\mathrm{CD} 14^{+}$cells compared to matched blood monocytes and brain microglia (77).

It is important to note that gene expression studies of TAMs from GBM have shown that such a simplified classification is not feasible in brain tumors, which likely harbor a spectrum of differently polarized myeloid cells that (as a net effect) culminates in a GBM-promoting role of TAMs (78).

\section{Myeloid-Derived Suppressor Cells (MDSCs), Neutrophils, Natural Killer (NK) Cells, and DCs}

Myeloid-derived suppressor cells are immature cells of myeloid origin that possess T cell suppressive properties. Patients with GBM have increased counts of MDSCs compared to healthy subjects (79). A recent detailed analysis of the phenotype of MDSCs and transcriptome of the different population of myeloid 
cells in GBM patient samples revealed the abundance of the MDSCs and microglia in the microenvironment highlighting the importance of the innate immune components (78). These data showed a higher infiltration of MDSCs in the microenvironment and detailed their role in the determination of the immune suppressive phenotype. MDSCs were elevated in many GBM patients in association with neutrophils and the number of neutrophils correlates with glioma grade and a negative prognosticator for survival (78). This is again consistent with demonstration of neutrophil infiltration in high grade gliomas in previous studies (80). The role of MDSCs in GSC biology was never studied until two recent reports. One study showed that GSCs reside in proximity to and attract MDSCs by secreting macrophage migration inhibitory factor (MIF) (81). MDSCs suppressed immune rejection and caused expansion of GSCs, which could be reversed by inhibition of MIF. In another study, the authors showed that GSCs secrete exosomes that regulate monocyte maturation and MDSC formation that in turn suppresses T-cell response (82).

Natural killer cells are cytotoxic lymphocytes and belong to the innate immune system. They cause host rejection and killing of tumors and microbial infections by cytokine release selectively against cells that lack the MHC class I, thereby protecting normal host cells from attack (since all normal cells express this antigen) (83). In recent years, NK cells have been shown to play a role in GBM-mediated immune suppression. IDH-mutant GSCs have been shown to have a significantly lower expression of NKG2D ligand compared to the IDH-wt cells, rendering the IDH-mutant GSCs resistant to NK cell-mediated lysis. Decitabine-mediated hypomethylation upregulates the expression of NKG2D ligand restoring the NK-mediated lysis of IDH-mut GSCs (84). The novelty of this study resides not only in the description of a mechanism of immune suppression mediated by a single mutation but also show an intrinsic altered mechanism of the innate immune system that might explain in part the failure of immunotherapy for IDH-mutant gliomas. Moreover, it has been shown that human GSCs express lower levels of the PD-1 ligand and therefore are more sensitive to the cytotoxicity of the IL-activated NK cells (85). Combining the negative immune regulation of the PD-1/B7H1 pathway (86) and the anti-GSCs effect of stimulated NK cells, the blockade of the $\mathrm{PD}-1 / \mathrm{B} 7 \mathrm{H} 1$ pathway between NK and GSCs might interrupt immunosuppression and promote NK cells killing GSCs. It has been demonstrated, in fact, that inhibiting the PD-1/B7H1 pathway promotes the toxicity of NK cells against GSCs in vitro (87). In an intracranial GSC model, mice that received PD-1-inhibited NK cell treatment showed reduced tumor growth and survived longer without obvious body

\section{REFERENCES}

1. Lapidot T, Sirard C, Vormoor J, Murdoch B, Hoang T, Caceres-Cortes J, et al. A cell initiating human acute myeloid leukaemia after transplantation into SCID mice. Nature (1994) 367(6464):645-8. doi:10.1038/367645a0

2. Beck B, Blanpain C. Unravelling cancer stem cell potential. Nat Rev Cancer (2013) 13(10):727-38. doi:10.1038/nrc3597

3. Visvader JE, Lindeman GJ. Cancer stem cells: current status and evolving complexities. Cell Stem Cell (2012) 10(6):717-28. doi:10.1016/j.stem.2012. 05.007 weight loss or distinct neurological deficits (87). These studies open a new avenue of investigation and possibility of combinatorial therapy against the innate and adaptive immune system in GBM (88).

Dendritic cells are antigen-presenting cells to T lymphocytes and play a major role in initiating and shaping the adaptive response. These cells represent the most potent and versatile way the immune system has evolved to present antigens and develop an immune response (89). DCs may play immune suppressive mechanisms through dysregulation of the antigenpresenting pathway or inducing exhaustion of the T cells (90-92). Unfortunately, studies involving GSC-DC interactions are limited to developing vaccine strategies and inducing a satisfactory T-cell-mediated immune response (93).

\section{CONCLUSION}

Studies involving GSCs have dramatically changed our view of this disease, and we have obtained a wealth of fascinating insight into the cell biology of GBM. The field of CSCs has helped us understand cancer biology from the perspective of developmental biologist. Similarities have been drawn to the cell types and differentiation pathways of normal stem cells. The recent information of GBM heterogeneity retrospectively explains why conflicting data were initially obtained in the GSC research field. It is now well established that GSCs are a central (but not the exclusive) target for therapeutic approaches to treat GBM. This is not only due to the inherent plasticity of GSCs that leads to transdifferentiation but also to the overbearing influence of the microenvironment (as highlighted in this review) that alters their stem cell state, tumorigenic potential, and therapeutic resistance. It is our opinion that future studies must incorporate the microenvironmental aspects while studying GSC biology.

\section{AUTHOR CONTRIBUTIONS}

AA and SC wrote the basic contents of the manuscript. KB conceived the manuscript, provided input throughout the preparation, and edited for the accuracy of the contents along with RG.

\section{FUNDING}

This research was supported by the University Cancer Foundation via the Institutional Research Grant program and Start up funds at the University of Texas MD Anderson Cancer Center (to KB) and Anni Hofmann Stiftung (to RG).

4. Bonaguidi MA, Wheeler MA, Shapiro JS, Stadel RP, Sun GJ, Ming GL, et al. In vivo clonal analysis reveals self-renewing and multipotent adult neural stem cell characteristics. Cell (2011) 145(7):1142-55. doi:10.1016/j.cell.2011. 05.024

5. Ortega F, Costa MR. Live imaging of adult neural stem cells in rodents. Front Neurosci (2016) 10:78. doi:10.3389/fnins.2016.00078

6. Ignatova TN, Kukekov VG, Laywell ED, Suslov ON, Vrionis FD, Steindler DA. Human cortical glial tumors contain neural stem-like cells expressing astroglial and neuronal markers in vitro. Glia (2002) 39(3):193206. doi:10.1002/glia.10094 
7. Hemmati HD, Nakano I, Lazareff JA, Masterman-Smith M, Geschwind DH, Bronner-Fraser $\mathrm{M}$, et al. Cancerous stem cells can arise from pediatric brain tumors. Proc Natl Acad Sci U S A (2003) 100(25):15178-83. doi:10.1073/ pnas. 2036535100

8. Galli R, Binda E, Orfanelli U, Cipelletti B, Gritti A, De Vitis S, et al. Isolation and characterization of tumorigenic, stem-like neural precursors from human glioblastoma. Cancer Res (2004) 64(19):7011-21. doi:10.1158/00085472.CAN-04-1364

9. Bao S, Wu Q, McLendon RE, Hao Y, Shi Q, Hjelmeland AB, et al. Glioma stem cells promote radioresistance by preferential activation of the DNA damage response. Nature (2006) 444(7120):756-60. doi:10.1038/nature05236

10. Bhat KP, Balasubramaniyan V, Vaillant B, Ezhilarasan R, Hummelink K, Hollingsworth F, et al. Mesenchymal differentiation mediated by NF-kappaB promotes radiation resistance in glioblastoma. Cancer Cell (2013) 24(3): 331-46. doi:10.1016/j.ccr.2013.08.001

11. Lathia JD, Mack SC, Mulkearns-Hubert EE, Valentim CL, Rich JN. Cancer stem cells in glioblastoma. Genes Dev (2015) 29(12):1203-17. doi:10.1101/ gad.261982.115

12. Friedmann-Morvinski D. Glioblastoma heterogeneity and cancer cell plasticity. Crit Rev Oncog (2014) 19(5):327-36. doi:10.1615/CritRevOncog. 2014011777

13. Bradshaw A, Wickremsekera A, Tan ST, Peng L, Davis PF, Itinteang T. Cancer stem cell hierarchy in glioblastoma multiforme. Front Surg (2016) 3:21. doi:10.3389/fsurg.2016.00021

14. Meacham CE, Morrison SJ. Tumour heterogeneity and cancer cell plasticity. Nature (2013) 501(7467):328-37. doi:10.1038/nature12624

15. Singh SK, Hawkins C, Clarke ID, Squire JA, Bayani J, Hide T, et al. Identification of human brain tumour initiating cells. Nature (2004) 432(7015):396-401. doi:10.1038/nature03128

16. Kemper K, Sprick MR, de Bree M, Scopelliti A, Vermeulen L, Hoek M, et al. The AC133 epitope, but not the CD133 protein, is lost upon cancer stem cell differentiation. Cancer Res (2010) 70(2):719-29. doi:10.1158/0008-5472. CAN-09-1820

17. Lathia JD, Gallagher J, Heddleston JM, Wang J, Eyler CE, Macswords J, et al. Integrin alpha 6 regulates glioblastoma stem cells. Cell Stem Cell (2010) 6(5):421-32. doi:10.1016/j.stem.2010.02.018

18. Enderling H, Hlatky L, Hahnfeldt P. Cancer stem cells: a minor cancer subpopulation that redefines global cancer features. Front Oncol (2013) 3:76. doi:10.3389/fonc.2013.00076

19. Piccirillo SG, Dietz S, Madhu B, Griffiths J, Price SJ, Collins VP, et al. Fluorescence-guided surgical sampling of glioblastoma identifies phenotypically distinct tumour-initiating cell populations in the tumour mass and margin. Br J Cancer (2012) 107(3):462-8. doi:10.1038/bjc.2012.271

20. Stieber D, Golebiewska A, Evers L, Lenkiewicz E, Brons NH, Nicot N, et al. Glioblastomas are composed of genetically divergent clones with distinct tumourigenic potential and variable stem cell-associated phenotypes. Acta Neuropathol (2014) 127(2):203-19. doi:10.1007/s00401-013-1196-4

21. Sottoriva A, Spiteri I, Piccirillo SG, Touloumis A, Collins VP, Marioni JC, et al. Intratumor heterogeneity in human glioblastoma reflects cancer evolutionary dynamics. Proc Natl Acad Sci U S A (2013) 110(10):4009-14. doi:10.1073/ pnas. 1219747110

22. Auffinger B, Spencer D, Pytel P, Ahmed AU, Lesniak MS. The role of glioma stem cells in chemotherapy resistance and glioblastoma multiforme recurrence. Expert Rev Neurother (2015) 15(7):741-52. doi:10.1586/14737175. 2015.1051968

23. Rosenblum ML, Gerosa M, Dougherty DV, Reese C, Barger GR, Davis RL, et al. Age-related chemosensitivity of stem cells from human malignant brain tumours. Lancet (1982) 1(8277):885-7. doi:10.1016/S0140-6736(82)92154-7

24. Eramo A, Ricci-Vitiani L, Zeuner A, Pallini R, Lotti F, Sette G, et al. Chemotherapy resistance of glioblastoma stem cells. Cell Death Differ (2006) 13(7):1238-41. doi:10.1038/sj.cdd.4401872

25. Qi L, Bellail AC, Rossi MR, Zhang Z, Pang H, Hunter S, et al. Heterogeneity of primary glioblastoma cells in the expression of caspase- 8 and the response to TRAIL-induced apoptosis. Apoptosis (2011) 16(11):1150-64. doi:10.1007/ s10495-011-0645-6

26. Fouse SD, Nakamura JL, James CD, Chang S, Costello JF. Response of primary glioblastoma cells to therapy is patient specific and independent of cancer stem cell phenotype. Neuro Oncol (2014) 16(3):361-71. doi:10.1093/neuonc/not223
27. Ma DK, Bonaguidi MA, Ming GL, Song H. Adult neural stem cells in the mammalian central nervous system. Cell Res (2009) 19(6):672-82. doi:10.1038/cr.2009.56

28. Calabrese C, Poppleton H, Kocak M, Hogg TL, Fuller C, Hamner B, et al. A perivascular niche for brain tumor stem cells. Cancer Cell (2007) 11(1):69-82. doi:10.1016/j.ccr.2006.11.020

29. Heddleston JM, Li Z, McLendon RE, Hjelmeland AB, Rich JN. The hypoxic microenvironment maintains glioblastoma stem cells and promotes reprogramming towards a cancer stem cell phenotype. Cell Cycle (2009) 8(20):3274-84. doi:10.4161/cc.8.20.9701

30. Li Z, Bao S, Wu Q, Wang H, Eyler C, Sathornsumetee S, et al. Hypoxiainducible factors regulate tumorigenic capacity of glioma stem cells. Cancer Cell (2009) 15(6):501-13. doi:10.1016/j.ccr.2009.03.018

31. Jakobsson L, Franco CA, Bentley K, Collins RT, Ponsioen B, Aspalter IM, et al. Endothelial cells dynamically compete for the tip cell position during angiogenic sprouting. Nat Cell Biol (2010) 12(10):943-53. doi:10.1038/ ncb2103

32. Fan X, Matsui W, Khaki L, Stearns D, Chun J, Li YM, et al. Notch pathway inhibition depletes stem-like cells and blocks engraftment in embryonal brain tumors. Cancer Res (2006) 66(15):7445-52. doi:10.1158/0008-5472.CAN-06-0858

33. Fan X, Khaki L, Zhu TS, Soules ME, Talsma CE, Gul N, et al. NOTCH pathway blockade depletes CD133-positive glioblastoma cells and inhibits growth of tumor neurospheres and xenografts. Stem Cells (2010) 28(1):5-16. doi:10.1002/stem.254

34. Zhu TS, Costello MA, Talsma CE, Flack CG, Crowley JG, Hamm LL, et al. Endothelial cells create a stem cell niche in glioblastoma by providing NOTCH ligands that nurture self-renewal of cancer stem-like cells. Cancer Res (2011) 71(18):6061-72. doi:10.1158/0008-5472.CAN-10-4269

35. Charles N, Ozawa T, Squatrito M, Bleau AM, Brennan CW, Hambardzumyan D, et al. Perivascular nitric oxide activates notch signaling and promotes stem-like character in PDGF-induced glioma cells. Cell Stem Cell (2010) 6(2):141-52. doi:10.1016/j.stem.2010.01.001

36. Eyler CE, Wu Q, Yan K, MacSwords JM, Chandler-Militello D, Misuraca KL, et al. Glioma stem cell proliferation and tumor growth are promoted by nitric oxide synthase-2. Cell (2011) 146(1):53-66. doi:10.1016/j.cell.2011.06.006

37. Ricci-Vitiani L, Pallini R, Biffoni M, Todaro M, Invernici G, Cenci T, et al. Tumour vascularization via endothelial differentiation of glioblastoma stemlike cells. Nature (2010) 468(7325):824-8. doi:10.1038/nature09557

38. Wang R, Chadalavada K, Wilshire J, Kowalik U, Hovinga KE, Geber A, et al. Glioblastoma stem-like cells give rise to tumour endothelium. Nature (2010) 468(7325):829-33. doi:10.1038/nature09624

39. Soda Y, Marumoto T, Friedmann-Morvinski D, Soda M, Liu F, Michiue H, et al. Transdifferentiation of glioblastoma cells into vascular endothelial cells. Proc Natl Acad Sci U S A (2011) 108(11):4274-80. doi:10.1073/pnas.1016030108

40. Rodriguez FJ, Orr BA, Ligon KL, Eberhart CG. Neoplastic cells are a rare component in human glioblastoma microvasculature. Oncotarget (2012) 3(1):98-106. doi:10.18632/oncotarget.427

41. Bergers G, Song S. The role of pericytes in cell-mediated formation and maintenance. Neuro Oncol (2005) 7(4):452-64. doi:10.1215/ S1152851705000232

42. Cheng L, Huang Z, Zhou W, Wu Q, Donnola S, Liu JK, et al. Glioblastoma stem cells generate vascular pericytes to support vessel function and tumor growth. Cell (2013) 153(1):139-52. doi:10.1016/j.cell.2013.02.021

43. Svensson A, Özen I, Genové G, Paul G, Bengzon J. Endogenous brain pericytes are widely activated and contribute to mouse glioma microvasculature. PLoS One (2015) 10(4):e0123553. doi:10.1371/journal.pone.0123553

44. Birbrair A, Zhang T, Wang ZM, Messi ML, Olson JD, Mintz A, et al. Type-2 pericytes participate in normal and tumoral angiogenesis. Am J Physiol Cell Physiol (2014) 307(1):C25-38. doi:10.1152/ajpcell.00084.2014

45. Liddelow SA, Guttenplan KA, Clarke LE, Bennett FC, Bohlen CJ, Schirmer L, et al. Neurotoxic reactive astrocytes are induced by activated microglia. Nature (2017) 541(7638):481-7. doi:10.1038/nature21029

46. Xu Q, Yuan X, Xu M, McLafferty F, Hu J, Lee BS, et al. Chemokine CXC receptor 4 - mediated glioma tumor tracking by bone marrow - derived neural progenitor/stem cells. Mol Cancer Ther (2009) 8(9):2746-53. doi:10.1158/1535-7163.MCT-09-0273

47. Sofroniew MV, Vinters HV. Astrocytes: biology and pathology. Acta Neuropathol (2010) 119(1):7-35. doi:10.1007/s00401-009-0619-8 
48. Yong VW. Response of astrocytes and oligodendrocytes to injury. Ment Retard Dev Disabil Res Rev (1998) 4(3):193-9. doi:10.1002/ (SICI)1098-2779(1998)4:3<193::AID-MRDD7>3.0.CO;2-P

49. Biasoli D, Sobrinho MF, da Fonseca AC, de Matos DG, Romão L, de Moraes Maciel R, et al. Glioblastoma cells inhibit astrocytic p53-expression favoring cancer malignancy. Oncogenesis (2014) 3:e123. doi:10.1038/oncsis.2014.36

50. Sin WC, Aftab Q, Bechberger JF, Leung JH, Chen H, Naus CC. Astrocytes promote glioma invasion via the gap junction protein connexin43. Oncogene (2016) 35(12):1504-16. doi:10.1038/onc.2015.210

51. Okolie O, Bago JR, Schmid RS, Irvin DM, Bash RE, Miller CR, et al. Reactive astrocytes potentiate tumor aggressiveness in a murine glioma resection and recurrence model. Neuro Oncol (2016) 18(12):1622-33. doi:10.1093/neuonc/ now212.903

52. Venkatesh HS, Johung TB, Caretti V, Noll A, Tang Y, Nagaraja S, et al. Neuronal activity promotes glioma growth through neuroligin-3 secretion. Cell (2015) 161(4):803-16. doi:10.1016/j.cell.2015.04.012

53. Vesely MD, Kershaw MH, Schreiber RD, Smyth MJ. Natural innate and adaptive immunity to cancer. Annu Rev Immunol (2011) 29:235-71. doi:10.1146/ annurev-immunol-031210-101324

54. Sharma P, Allison JP. The future of immune checkpoint therapy. Science (2015) 348(6230):56-61. doi:10.1126/science.aaa8172

55. Glass R, Synowitz M. CNS macrophages and peripheral myeloid cells in brain tumours. Acta Neuropathol (2014) 128(3):347-62. doi:10.1007/ s00401-014-1274-2

56. Marincola FM, Jaffee EM, Hicklin DJ, Ferrone S. Escape of human solid tumors from T-cell recognition: molecular mechanisms and functional significance. Adv Immunol (2000) 74:181-273. doi:10.1016/S0065-2776(08) 60911-6

57. Berghoff AS, Kiesel B, Widhalm G, Rajky O, Ricken G, Wöhrer A, et al. Programmed death ligand 1 expression and tumor-infiltrating lymphocytes in glioblastoma. Neuro Oncol (2015) 17(8):1064-75. doi:10.1093/neuonc/ nou307

58. Doucette T, Rao G, Rao A, Shen L, Aldape K, Wei J, et al. Immune heterogeneity of glioblastoma subtypes: extrapolation from the cancer genome atlas. Cancer Immunol Res (2013) 1(2):112-22. doi:10.1158/2326-6066. CIR-13-0028

59. Takahashi T, Tagami T, Yamazaki S, Uede T, Shimizu J, Sakaguchi N, et al. Immunologic self-tolerance maintained by $\mathrm{CD} 25(+) \mathrm{CD} 4(+)$ regulatory $\mathrm{T}$ cells constitutively expressing cytotoxic T lymphocyte-associated antigen 4 . J Exp Med (2000) 192(2):303-10. doi:10.1084/jem.192.2.303

60. Badie B, Schartner J, Prabakaran S, Paul J, Vorpahl J. Expression of Fas ligand by microglia: possible role in glioma immune evasion. J Neuroimmunol (2001) 120(1-2):19-24. doi:10.1016/S0165-5728(01)00361-7

61. Wischhusen J, Jung G, Radovanovic I, Beier C, Steinbach JP, Rimner A, et al. Identification of CD70-mediated apoptosis of immune effector cells as a novel immune escape pathway of human glioblastoma. Cancer Res (2002) 62(9):2592-9.

62. Thompson CB, Allison JP. The emerging role of CTLA-4 as an immune attenuator. Immunity (1997) 7(4):445-50. doi:10.1016/S1074-7613(00) 80366-0

63. Stillman BN, Hsu DK, Pang M, Brewer CF, Johnson P, Liu FT, et al. Galectin-3 and galectin-1 bind distinct cell surface glycoprotein receptors to induce $\mathrm{T}$ cell death. J Immunol (2006) 176(2):778-89. doi:10.4049/jimmunol.176.2.778

64. Fukumori T, Takenaka Y, Yoshii T, Kim HR, Hogan V, Inohara H, et al. CD29 and CD7 mediate galectin-3-induced type II T-cell apoptosis. Cancer Res (2003) 63(23):8302-11.

65. Wei J, Barr J, Kong LY, Wang Y, Wu A, Sharma AK, et al. Glioblastoma cancer-initiating cells inhibit T-cell proliferation and effector responses by the signal transducers and activators of transcription 3 pathway. Mol Cancer Ther (2010) 9(1):67-78. doi:10.1158/1535-7163.MCT-09-0734

66. Lottaz C, Beier D, Meyer K, Kumar P, Hermann A, Schwarz J, et al. Transcriptional profiles of $\mathrm{CD} 133+$ and CD133- glioblastoma-derived cancer stem cell lines suggest different cells of origin. Cancer Res (2010) 70(5):2030-40. doi:10.1158/0008-5472.CAN-09-1707

67. Facoetti A, Nano R, Zelini P, Morbini P, Benericetti E, Ceroni M, et al. Human leukocyte antigen and antigen processing machinery component defects in astrocytic tumors. Clin Cancer Res (2005) 11(23):8304-11. doi:10.1158/10780432.CCR-04-2588
68. Badie B, Schartner J. Role of microglia in glioma biology. Microsc Res Tech (2001) 54(2):106-13. doi:10.1002/jemt.1125

69. Parney IF, Waldron JS, Parsa AT. Flow cytometry and in vitro analysis of human glioma-associated macrophages. Laboratory investigation. J Neurosurg (2009) 110(3):572-82. doi:10.3171/2008.7.JNS08475

70. Lapa C, Linsenmann T, Lückerath K, Samnick S, Herrmann K, Stoffer C, et al. Tumor-associated macrophages in glioblastoma multiforme - a suitable target for somatostatin receptor-based imaging and therapy? PLoS One (2015) 10(3):e0122269. doi:10.1371/journal.pone.0122269

71. Sica A, Mantovani A. Macrophage plasticity and polarization: in vivo veritas. J Clin Invest (2012) 122(3):787-95. doi:10.1172/JCI59643

72. Hao NB, Lü MH, Fan YH, Cao YL, Zhang ZR, Yang SM. Macrophages in tumor microenvironments and the progression of tumors. Clin Dev Immunol (2012) 2012:948098. doi:10.1155/2012/948098

73. Samaras V, Piperi C, Korkolopoulou P, Zisakis A, Levidou G, Themistocleous MS, et al. Application of the ELISPOT method for comparative analysis of interleukin (IL)-6 and IL-10 secretion in peripheral blood of patients with astroglial tumors. Mol Cell Biochem (2007) 304(1-2):343-51. doi:10.1007/s11010-007-9517-3

74. Ellert-Miklaszewska A, Dabrowski M, Lipko M, Sliwa M, Maleszewska M, Kaminska B. Molecular definition of the pro-tumorigenic phenotype of glioma-activated microglia. Glia (2013) 61(7):1178-90. doi:10.1002/glia.22510

75. Wu A, Wei J, Kong LY, Wang Y, Priebe W, Qiao W, et al. Glioma cancer stem cells induce immunosuppressive macrophages/microglia. Neuro Oncol (2010) 12(11):1113-25. doi:10.1093/neuonc/noq082

76. Zhou W, Ke SQ, Huang Z, Flavahan W, Fang X, Paul J, et al. Periostin secreted by glioblastoma stem cells recruits M2 tumour-associated macrophages and promotes malignant growth. Nat Cell Biol (2015) 17(2):170-82. doi:10.1038/ ncb3090

77. Ellert-Miklaszewska A, Wisniewski P, Kijewska M, Gajdanowicz P, Pszczolkowska D, Przanowski P, et al. Tumour-processed osteopontin and lactadherin drive the protumorigenic reprogramming of microglia and glioma progression. Oncogene (2016) 35(50):6366-77. doi:10.1038/onc.2016.55

78. Gabrusiewicz K, Rodriguez B, Wei J, Hashimoto Y, Healy LM, Maiti SN, et al. Glioblastoma-infiltrated innate immune cells resemble M0 macrophage phenotype. JCI Insight (2016) 1(2):e85841. doi:10.1172/jci.insight.85841

79. Raychaudhuri B, Rayman P, Ireland J, Ko J, Rini B, Borden EC, et al. Myeloidderived suppressor cell accumulation and function in patients with newly diagnosed glioblastoma. Neuro Oncol (2011) 13(6):591-9. doi:10.1093/ neuonc/nor042

80. Fossati G, Ricevuti G, Edwards SW, Walker C, Dalton A, Rossi ML. Neutrophil infiltration into human gliomas. Acta Neuropathol (1999) 98(4):349-54. doi:10.1007/s004010051093

81. Otvos B, Silver DJ, Mulkearns-Hubert EE, Alvarado AG, Turaga SM, Sorensen MD, et al. Cancer stem cell-secreted macrophage migration inhibitory factor stimulates myeloid derived suppressor cell function and facilitates glioblastoma immune evasion. Stem Cells (2016) 34(8):2026-39. doi:10.1002/ stem.2393

82. Domenis R, Cesselli D, Toffoletto B, Bourkoula E, Caponnetto F, Manini I, et al. Systemic $\mathrm{T}$ cells immunosuppression of glioma stem cell-derived exosomes is mediated by monocytic myeloid-derived suppressor cells. PLoS One (2017) 12(1):e0169932. doi:10.1371/journal.pone.0169932

83. Algarra I, Cabrera T, Garrido F. The HLA crossroad in tumor immunology. Hum Immunol (2000) 61(1):65-73. doi:10.1016/S0198-8859(99)00156-1

84. Zhang X, Rao A, Sette P, Deibert C, Pomerantz A, Kim WJ, et al. IDH mutant gliomas escape natural killer cell immune surveillance by downregulation of NKG2D ligand expression. Neuro Oncol (2016) 18(10):1402-12. doi:10.1093/ neuonc/now061

85. Avril T, Vauleon E, Hamlat A, Saikali S, Etcheverry A, Delmas C, et al. Human glioblastoma stem-like cells are more sensitive to allogeneic NK and $\mathrm{T}$ cell-mediated killing compared with serum-cultured glioblastoma cells. Brain Pathol (2012) 22(2):159-74. doi:10.1111/j.1750-3639.2011.00515.x

86. Kedmi M, Avigdor A, Nagler A. Anti-PD-1-targeted therapies focusing on lymphatic malignancies: biological rationale, clinical challenges and opportunities. Acta Haematol (2015) 133(2):129-35. doi:10.1159/000362151

87. Huang BY, Zhan YP, Zong WJ, Yu CJ, Li JF, Qu YM, et al. The PD-1/B7-H1 pathway modulates the natural killer cells versus mouse glioma stem cells. PLoS One (2015) 10(8):e0134715. doi:10.1371/journal.pone.0134715 
88. Huang B, Zhang H, Gu L, Ye B, Jian Z, Stary C, et al. Advances in immunotherapy for glioblastoma multiforme. J Immunol Res (2017) 2017:3597613. doi:10.1155/2017/3597613

89. Trombetta ES, Mellman I. Cell biology of antigen processing in vitro and in vivo. Annu Rev Immunol (2005) 23:975-1028. doi:10.1146/annurev. immunol.22.012703.104538

90. Wing K, Onishi Y, Prieto-Martin P, Yamaguchi T, Miyara M, Fehervari Z, et al. CTLA-4 control over Foxp3+ regulatory T cell function. Science (2008) 322(5899):271-5. doi:10.1126/science.1160062

91. Jonuleit H, Schmitt E, Schuler G, Knop J, Enk AH. Induction of interleukin 10-producing, nonproliferating CD4(+) T cells with regulatory properties by repetitive stimulation with allogeneic immature human dendritic cells. J Exp Med (2000) 192(9):1213-22. doi:10.1084/jem.192.9.1213

92. Unger WW, Laban S, Kleijwegt FS, van der Slik AR, Roep BO. Induction of Treg by monocyte-derived DC modulated by vitamin D3 or dexamethasone: differential role for PD-L1. Eur J Immunol (2009) 39(11):3147-59. doi:10.1002/ eji.200839103

93. Pellegatta S, Finocchiaro G. Dendritic cell vaccines for cancer stem cells. Methods Mol Biol (2009) 568:233-47. doi:10.1007/978-1-59745-280-9_15

Conflict of Interest Statement: The authors declare that the research was conducted in the absence of any commercial or financial relationships that could be construed as a potential conflict of interest.

Copyright (c) 2017 Audia, Conroy, Glass and Bhat. This is an open-access article distributed under the terms of the Creative Commons Attribution License (CC BY). The use, distribution or reproduction in other forums is permitted, provided the original author(s) or licensor are credited and that the original publication in this journal is cited, in accordance with accepted academic practice. No use, distribution or reproduction is permitted which does not comply with these terms. 